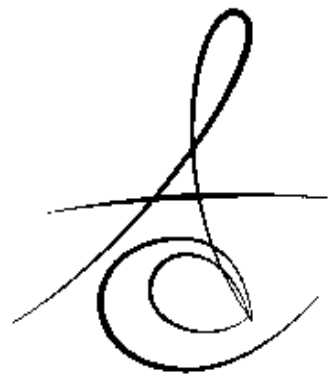

Makale Kodu/Article code: 1409

Makale Gönderilme tarihi; 22.11 .2013

Kabul Tarihi: 28.01.2014

\title{
AĞIZ SAĞLIĞI BİLİNCI VE ORTODONTİ HASTALARININ AĞIZ SAĞLIĞININ GELİŞTİRİLMESİ
}

\author{
ORAL HEALTH AWARENESS AND REHABILITATION ORAL HEALTH OF \\ ORTHODONTICS PATIENTS
}

Dr. Mehmet BANí

Dt. Ayşegül AYHAN BANi ${ }^{* *}$

\section{ÖZET}

Diş hekimliğinde ağız bakım uygulamalarının kalıcı olması çocukluk döneminde kazanılan bir alışkanlıkla sağlanmaktadır. Çocuklar her konuda olduğu gibi ağız diş sağlığı konusunda da ebeveynlerine benzerlik göstermektedir. Bu nedenle toplumun ağız sağlığı konusundaki bilinç düzeyi sonraki nesiller için önem taşımaktadır. Ağız bakımının yokluğu, yetersizliği veya yanlış olması diş hekimliğinin en büyük problemi olan çürük ve periodontal hastalıkları oluşturmaktadır. Özellikle ortodontik tedavi gören hastalar çürük ve periodontal hastalık yönünden yüksek risk grubundadır. Ortodontik tedavi sırasında kullanılan materyaller diş yüzeyleri üzerinde tutucu sahalar oluşturarak, besinlerin buralarda birikmesine neden olmaktadırlar. Bu derlemenin amacı ağız sağlığı bilincinin önemini vurgulamak ve ortodontik tedavi gören hastalarda ağız sağlığının geliştirilmesini aktarmaktadır.

Anahtar Kelimeler: Ağız Sağığı Bilinci, Ortodonti, Ağız Sağlığının Geliştirilmesi

\section{ABSTRACT}

Oral care applications in dentistry a habit acquired in childhood persist provided. As with all matters of oral health in children are similar to their parents. For this reason, the level of community awareness of oral health is important for the next generations. The absence, insufficient or incorrect oral care causes decay and periodontal disease the biggest problem in dentistry. The patients undergoing orthodontic treatment especially is high-risk group in terms of caries and periodontal disease. The materials used on the surfaces of the teeth during orthodontic treatment retention areas, creating here contribute to the accumulation of nutrients. The aim of this review is to highlight the importance of oral health awareness and the development of oral health in patients undergoing orthodontic treatment.

Key words: Awareness of Oral Health, Orthodontics, Oral Health Impoving

\section{GİRIŞ}

Diş hekimliği uzmanlığının çözmeye çalıştığı problemlerden biri de tüm çocukların ve yetişkinlerin iyi bir ağız sağlğına sahip olmalarını sağlamaktır ${ }^{1,2}$. Gelişmiş ülkelerde diş hekimliği hizmetlerinin yaygınlaştıııması, sosyo-ekonomik düzey ve kişisel hijyen uygulama bilincinin artışı ile son yıllarda ağız ve diş sağlığı problemleri hızla azalmaya başlamışıı ${ }^{1-5}$. Ancak gelişmekte olan ülkelerde, ağız ve diş sağlığı problemleri halen ciddi ekonomik ve sosyal sorunlar oluşturmaya devam etmektedir ${ }^{3,4}$. Diş çürüğü ve periodontal hastalıklar dünyanın birçok yerinde en sık gözlenen ağız sağlığı problemleridir. Bu problemler Türkiye'nin de içinde bulunduğu gelişmekte olan ve/veya gelişmemiş ülkelerde gelişmiş ülkelere göre daha fazla gözükmektedir. Diş çürükleri erişkinlerin hemen hemen hepsinde bulunurken çocukların \% 6090'ında gözlenmektedir. Periodontal hastalıklardan gingivitis hem erişkinlerde hem de çocuklarda çok yaygın olup, periodontitis ise yaşla birlikte şiddeti ve görülme sıklığı artmaktadır. Türk toplumunda ise diş çürüğü ve periodontal hastalık oranının \% 96 olduğu bildirilmektdir ${ }^{3,5}$.

*Gazi Üniversitesi Diş Hekimliği Fakültesi Pedodonti Anabilim Dalı, Dr.

${ }^{* *}$ Gazi Üniversitesi Diş Hekimliği Fakültesi Ortodonti Anabilim Dalı, Dt. 
Diş çürüğü ve periodontal hastalık farklı patolojik mekanizmalara sahip olsalar da, primer etiyolojik faktör mikrobiyal dental plaktır. Plak birikiminin ana sebebi ise ağız bakımının yokluğu, yetersizliği veya yanlış olmasıdır. Mevcut ağız sağlğını korumak, oluşan hastalığı durdurmak, hastayı sağlığına yeniden kavuşturmak ve sağlığın idamesi için en önemli ön şart 'düzenli, yeterli ve doğru bir ağız bakımı' gerçekleştirmektir. Ağız sağlığı için iyi bir ağız bakımı kadar bunun öncesinde kişinin ağız sağığı ve bakımı hakkındaki bilgilerinin de doğru olması çok önemlidir ${ }^{2,6-8}$.

Ağız bakımı uygulamalarının kalıclığı erken çocukluk döneminde sağlanmaktadır. Çocuklar bu dönemde, ailesinin, öğretmenlerinin ya da hekimlerin söz ve davranışlarından etkilenmekte ve onları taklit etmeye başlamaktadır. Yapılan çalışmalarda anneler, genç erişkinlerin ağız sağığı ile ilişkili davranışlarında model olarak etkili olduğu gösterilmiştir. Çocuklar diş fırçalamaya ailelerini taklit ederek başlarlar. Bu taklit zaman içinde başta ailede olmak üzere eğitim öğretimin tüm kademelerinde ve tüm yaşamları boyunca verilecek doğru bilgilerle bilinçli bir alışkanlık halini almakta ve sonraki nesillere aktarılmaktadır. Literatürde ebeveynlerin çocukların ağız bakımı üzerinde etkili oldukları belirtilmektedir ${ }^{1,3-5,7,9-12}$.

Tulunoğlu ve ark. ${ }^{12}$ aile eğitim düzeyinin okul öncesi cocuklardaki ağız diş sağlığı uygulamaları üzerine etkilerini değerlendirdikleri epidemiyolojik bir çalışmada; eğitim seviyesi arttıkca hastaların ağız ve diş sağlığına verdikleri önemin arttığı ve bunun da dolgulu diş sayısını arttırdığı bildirilmiştir.

Bozkurt ve Kıran ${ }^{11}$ yetiştirme yurdunda kalan 12-16 yaş grubu bireylerde ağız sağlığı ve ağız hijyenine olan ilgiyi değerlendirdikleri çalışmalarında; bu bireyleri aynı ilçede aileleri yanında yaşayan ve aynı okullara giden bireyler ile kıyaslamışlardır. Çalışma fırçalama alışkanlığının birçok bireyde bulunmayışı, toplumumuzda hem aile ve öğretmenlere, hem de çocuklara ve gençlere yönelik ağız sağlğı ile ilgili kapsamlı eğitim programlarının yaygınlaştırıması intiyacını belirgin biçimde ortaya koymaktadır.

Düzenli diş bakımı milyonlarca çocuğun sağlıkı ağza sahip olmasına katkıda bulunsa da, önemli sayıda çocuk ve yetişkinin intiyaçları olan bakımı almakta ciddi problemleri bulunmaktadır. Bu çocuklar sıklıkla düşük gelirli ya da azınlık ailelerinden gelmektedir ve maalesef bu çocuklar diğer çocuklara göre daha fazla ağız diş hastalığı geçirme eğilimindedirler. Bu çocukların diş bakımına erişimini kısıtlayan faktörlerden bazıları finans yokluğu, ulaşım zorluğu, dil ve kültür engelleri ve bakım ihtiyacının algılanmamasıdır ${ }^{1,2,13}$.

\section{Ortodonti Hastalarında Ağız Sağlığı}

Ortodontik tedavi görmek isteyen hastaların kliniklere başvurdukları andan itibaren iyi bir ağız hijyenine sahip olmaları ve ortodontik tedavi sırasında da bunu devam ettirmeleri tedavinin başarısı için önemlidir. Ortodontik tedavi sırasında kullanılan bant, braket ve ark telleri gibi materyaller diş yüzeyleri üzerinde tutucu sahalar oluşturarak, besinlerin buralarda birikmesine neden olmaktadırlar ${ }^{14-20}$. Yapılan çalışmalarda ortodontik tedavilerin dişeti iltihabı, kanama, dişeti büyümesi ve cep derinliğinde artışa neden olduğu bildirilmektedir. Aynı zamanda subgingival bölgedeki periodontal patojenlerin artışının ortodondik tedavi ile ilişkili olduğu belirtilmektedir ${ }^{15}$. Bununla birlikte diş minesinin demineralizasyonu sabit ortodontik tedavinin en sık görülen komplikasyonu olarak bilinmektedir. Ortodontik tedavi gören hastalarda beyaz nokta lezyonlarının görülme sıklı̆ı $\% 13-84$ arasındadır ${ }^{14,16}$. Araştırmalar ortodontik tedavi sırasında diş çürüklerinin anlamlı düzeyde arttığ| ${ }^{17,21-24}$ ve en çok etkilenen dişlerin büyük azılar, üst yan kesiciler, alt kaninler ve küçük azılar olduğu bildirilmektediir ${ }^{16,23,25}$. Ortodontik aygıtlar ağızda yeni retansiyon alanları oluşturmakta ve plağın birikimini kolaylaştıırken, ağız hijyenini de zorlaştırmaktadır ${ }^{17-}$ $20,23,24,26$. Ortodontik aygıtların yapıştırımasından sonra ağızda mutans streptokokların (S.mutans) ve laktobasillerin sayısında bir artı̧̧ olduğunu gösterilmektedir. Braketlerin çevresindeki çürük kavitesinden ya da yakınından toplanan plakta belirlenen S.mutans sayısının, ortodontik tedavi görmeyen bireylerin dişlerinden toplanan plakla karşılaştırıldığında anlamlı düzeyde yüksek olduğu bildirilmiştir ${ }^{16,27-29}$.

Ortodonti hastalarında diş çürüklerinin oluşmasında tükürüğün de önemli rolü bulunmaktadır. Tükürük akış hızı, tamponlama kapasitesi ve pH'sı asit atağı sonrasında etkilenerek minede demineralizasyonu artırmaktadır ${ }^{23}$. Ortodonti hastalarında tükürüğün en az ulaşıı̆ı üst çene kesici dişlerde daha çok demineralizasyon görülmesi tükürüğün bu etkisine iyi bir örnek olabilirir,30. Her bireyin farklı tükürük yapısına sahip olması nedeni ile farklı şekilde 
deminerilizasyon oluşturmaları doğaldır. Bu nedenle ortodontik tedavi öncesinde her birey için bir risk değerlendirmesi yapmak, uygulanacak koruyucu yöntemlerin belirlenmesinde de önemli rol oynayabilmektedir. Çürük riski taşıyan bireylerin belirlenmesinde; tükürük akış hızı, geçmişteki çürük deneyimi ve geçmiş bir yıl içinde oluşan yeni çürük lezyonlarının sayısı, florür alınım düzeyi, beslenme şekli, ağızdaki S.mutans ve laktobasillerin sayısı ile plak indeks değerlerinin göz önünde bulundurulması önerilmektedir $^{23,31}$. Bu konuda yapılan bir çalsşmaya göre; plak indeksi, aproksimal plak indeksi, DMFT indeksi, başlangıç lezyonlarının varlığı, gingival indeks gibi parametrelerin tedavi öncesinde uygulanması ortodontik tedaviye bağı dekalsifikasyon riskini ortaya koyabilmektedir ${ }^{32}$.

Ortodontik tedavi gören bireylerin diş çürüğü ve periodontal hastalıklar konusunda yüksek risk grubunda yer aldığı kabul edilmekte ve bu konuda çeşitli yöntemlerin bir arada kullanıldığı koruyucu programlar ele alınmaktadır.

Bu yöntemler:

1. Diyetin Düzenlenmesi

2. Mekanik yöntemler - Dental plağın uzaklaştırılması:

- Diş fırçalama teknikleri, Diş ipi kullanımı, Arayüz fırçası kullanımı

3. Kimyasal yöntemler - Mikroorganizmaların etkisinin azaltılması ve diş minesinin güçlendirilmesi: Florür uygulamaları, Klorheksidin uygulamaları, diğer yöntemler olarak sınıflanabilir ${ }^{1,2,14-16,23}$.

\section{Diyetin Düzenlenmesi}

Ortodontik tedavi sırasında kullanılan materyaller diş yüzeyleri üzerinde tutucu sahalar oluşturarak besinlerin buralarda birikmesine neden olmaktadırlar. Aynı zamanda ağızdaki mekaniklerin etkisiyle dil ve tükürük etkinlikleri azaldığından gıdaları parçalarken sorun yaşamaktadırlar. Parçalanması geçiken gıdalar diş yüzeylerinde daha fazla beklemekte plak oluşumuna ve dişlerin uzun sure asite maruz kalmasına neden olmaktadır ${ }^{14,15,20}$. Özellikle karbonhidratlı beslenen kişilerde çürük riskinde artış görülmektedir $^{1,2,33}$. Bunun sebebi karyojenik bakteriler ağızda yaşamlarını sürdürebilmek için sadece fermente olabilen karbonhidratı gıdalara intiyaç duymakatadırlar ${ }^{1,2,34}$.

Diyetin düzenlenmesinde tüketilen fermente karbonhidrat miktarı, gıda şeker konsantrasyonu, karbonhidrat içeriği, yemek ve aperatif sıklığı, ağızda gıdanın bulunma süresi gibi birçok faktör önem kazanmaktadır $^{34}$. Ortodontik tedavi öncesinde, 5 günlük ayrıntıı bir diyet kaydı içeren diyet düzenlemesi özellikle çürük riski olan hastalar için tavsiye edilmektedir. Fermente karbonhidratı beslenen kişiler diş çürüğü ve periodontal hastalıklar açısından yüksek risk grubunda olduğundan gıdaların karyojenik potansiyeli tüm hastalara anlatılmalıdır ${ }^{14}$. Diyetin düzenlenmesinde dikkat edilmesi gereken en önemli noktalardan biride 'soft drink' olarak adlandırılan yüksek şeker içerikli ve asitli içeceklerin kullanıımamasıdır $^{33}$. Özellikle sakkaroz içerikli, sitrik asitli ve fosforik asitli içecekler ağız pH'sını düşürdüğünden önerilmemektedir ${ }^{14}$. Sakkaroz ve sukroz gibi şeker alkollerinin yerine xylitol içeren şeker alkolü tercih edilmelidir. Dünyanın bir çok yerinde insanlar günlük su intiyacının büyük bir kısmını şekerli-asitli içeceklerle karşılamaktadır. Bu nedenle hastalara şekerli-asitli içecekler yerine su içmeleri tavsiye edilmelidir ${ }^{33}$. Ağıza alınan içeceklerin sıklığı ve süreside önemli olup mümkün olduğunca az ve kısa sürede tüketilmesi önerilmektedir ${ }^{14}$. Hastanın her randevusunda beslenme eğitimi kontrol edilmelidir.

\section{Dental Plağın Uzaklaştırılması}

Dental plağın diş fırçaları ve diğer destekleyici yöntemler ile mekanik olarak uzaklaştırıması plak kontrolünde en yaygın kabul gören yöntemdir. Günümüzde dental plağın etkin şekilde uzaklaştırılabilmesi için çok farkı tipte tasarlanmış geleneksel diş fırçaları, pille ve elektrikle çalışan diş fırçaları ve ultrasonik diş fırçaları kullanılmaktadı ${ }^{35,36}$.

Elle kullanılan firçaların ortodontik tedavi gören bireyler için özel olarak üretilmiş braketlerin çevresinde temizliği sağlayabilen firçalardan seçilmesi önerilmektedir $^{36}$. Ayrıca elektrikle çalışan firçaların da ucuna da ortodontik tedavi için özel olarak tasarlanmış fırçalar takılabilmektedir. Ortodonti hastalarının dental plağı uzaklaştırabilmesinde ultrasonik ve elektrikli diş fırçalarının plağı uzaklaştırabilme kabiliyetlerinin el fırçalarına göre belli düzeylerde üstünlük gösterdiği, ancak doğru kullanıldığında el firçası ile de olumlu sonuçlar alınabileceği gösterilmiştir ${ }^{36-39}$. Bununla birlikte klinik araştırmalar ortodonti hastaları için özel olarak üretilmiş fırçaların geleneksel el fırçaları ile karşılaştırıldığında anlamlı bir üstünlüğü olmadığını göstermiştir ${ }^{38-41}$. Araştırmacılar düzenli bir şekilde plak 
kontrolünü sağlayabilen hastalarda fırçanın tipinin önemli olmadığını, ancak bu konuda yeterli dikkati gösteremeyen bireylerde ultrasonik ya da elektrikli fırçaların daha yararlı olabileceğini savunmaktadırlar ${ }^{39}$.

Arayüz temizliğinin yapılmasında diş ipleri, arayüz fırçaları ve oral irrigasyonu sağlayan ağız duşları kullanılabilmektedir. Çeşitli özellikleri bulunan, uçları güçlendirilmiş diş iplerinin arasında dişlerin arayüzlerini ve "braket-bant-telelastik-kompleksini temizlemek üzere geliştirilmiş Orthofloss dikkat çekmektedir. Superfloss ve Orthofloss'un sabit ortodontik tedavi gören hastalardaki etkinliğinin incelendiği bir çalışmada her iki diş ipinin de ön bölgede daha etkili olduğu, ip kullanımının zor olduğu arka bölge dişlerinde etkinliğin daha az olduğu bildirilmiştir ${ }^{41}$.

Hickman ve ark.'nın ${ }^{40}$ klinik çalışmalarının sonucuna el fırçası veya sonik diş fırçalarına ek olarak ağız duşlarının (water jet) kullanılmasının, kanamanın ve dişeti iltihabının azaltılmasında ve plağın uzaklaştırılmasında fırça ile birlikte diş ipi kullanılmasına etkili bir alternatif olabileceği ileri sürülmüşlerdir. Kossack ve Jost-Bringmann ${ }^{42}$; ortodontik tedavi gören hastalarda çeşitli ağız temizleme araçlarının birlikte kullanımının tüm ortodonti hastalarına önerilmesi gerektiğini bildirmişlerdir.

\section{Mikroorganizmaların etkisinin azaltılması ve diş minesinin güçlendirilmesi}

Ağızda diş çürüklerine ve periodontal hastalıklara neden olan patojenlerin etkisinin azaltılmasında fluorid preparatları, klorheksidin ve ksilitol içeren ürünlerin kullanımı önerilmektedir.

\section{Florür Uygulamaları}

Florür iyonları, bakterilerin enzim sistemlerini bloke ederek minenin demineralizasyonu azaltma ve remineralizasyonu teşvik etmektedir. Topikal flor uygulandığında plakta, diş yüzeyinde (mine/dentin) ve başlangıç lezyonlarında kalsiyum flor $\left(\mathrm{CaF}_{2}\right)$ benzeri bir materyalin oluştuğu bilinmektedir. $\mathrm{CaF}_{2}$ çürük atakları esnasında pH seviyesi düştüğünde flor iyonu salmak için bir depo görevi görmektedir ${ }^{16}$. Bu nedenle ortodontik tedavi gören bireylerin ağız ortamında florürün düşük düzeyde sürekli bulunması istenmektedir $^{14}$. Fluor iyonlarının ağız içinde bulunması florür içeren diş macunları, florürlü ağız gargaraları, florür jel ve vernikleri (cila), braket ve bantların yapıştırılmasında kullanılan ve florür salınımı yapabilen materyaller gibi çeşitli yollarla sağlanabilmektedir ${ }^{16,23}$. Bu yöntemlerin kombine olarak kullanımlarının daha etkili olduğu savunulmaktadır ${ }^{14,16,23}$. Son yıllarda flor verniklerin kullanımı önem kazanmaktadır ${ }^{14}$. Flor içeren cila olan Duraphat'ın kontrollü klinik çalışmalarda diş çürüğünün engellenmesindeki klinik etkinliği doğrulanmıştır ${ }^{16}$.

Florlu diş macunları ağızda oluşabilecek tüm çürüklerin önlenmesinde bir temeldir. Çoğu diş macunu sodyum florür, monoflorofosfat, kalay florür veya amin florür içermektedir. Diş macunlarında doza bağlı değişen flor cevabı gösterilmiştir ve \%0,1'in altındaki flor konsantrasyonu ortodonti hastalarında tavsiye edilmemektedir ${ }^{16}$. Øgaard ve ark. ${ }^{43}$, amin florür/kalay florür içeren diş macununun plak, gingivitis ve başlangıç çürük lezyonlarının gelişimi üzerine etkili olduğunu belirlemişlerdir. Ortodontik tedavi sırasında florlu diş macunu kullanımının yanı sıra \%0,05 sodyum florürün günlük kullanması tavsiye edilmektedir $^{14,16}$. Sabit ortodontik tedaviden sonra oluşan beyaz nokta lezyonlarının düşük dozda florür içeren (50 ppm) ağız gargaraları ile küçültülebildiği klinik bir çalışma ile gösterilmiştir ${ }^{44}$.

Son dönemde braketlerin çevresinde ve altındaki diş minesinin dekalsifikasyonunu önlemek amacı ile florür salımı yapan, yüksek düzeyde doldurucu içeren örtücü bir rezin materyali (ProSeal) üretilmiştir. Soliman ve ark. ${ }^{45}$, bu materyalin düşük düzeyde de olsa florür salımı yapabildiğini ve florür köpüğü uygulanığında florürü geri yükleyebildiğini bildirmişlerdir. Yüksek risk grubunda yer alan hastalarda, braketlerin yapıştırılmasından önce bu tür koruyucu materyallerin uygulanması ve bunlara ek olarak düzenli yüzeyel florür uygulamaları ile braketin çevresindeki minenin dekalsifiye olmasının önlenebileceği düşünülmektedir. $\mathrm{Hu}$ ve Featherstone ${ }^{46}$, ProSeal materyalinin demineralizasyonu önlemedeki etkinliğini daha düşük düzeyde doldurucu içeren başka bir örtücü rezin materyaline oranla anlamlı düzeyde önlediğini bildirmişlerdir. Varlık ve Demirbaş ${ }^{47}$; ProSeal materyali ile in vivo olarak yaptıkları çalışmalarında ProSeal'in kompozit rezinlerin bağlanma özellkileri üzerinde etkisinin olmadığını bildirmişlerdir. Tuncer ve ark. ${ }^{48}$ da Ortho-Coat ile yaptıkları benzer bir çalışmanın sonucunda; mineyi korumak için rezin uygulamanın ortodontik braketlerin bağlanma kuvvetini etkilemediğini bildirmişlerdir.

Ortodontik tedavi gören hastalarda florürün, braketlerin ve bantların çevresindeki mine ile plak arasında sürekli bulunmasının sağlanması amacı ile 
braket ve bantların yapıştırımasında kullanılan geleneksel cam iyonomer (CIS), rezin modifiye cam iyonomer (RMCIS) ve poliasit modifiye kompozit rezin (kompomer) materyallerinin florür salabilme ve florürle geri yüklenebilme özelliklerinden de faydalanılmaktadır $^{16,23}$. Bu materyallerin florür salım özelliklerini inceleyen çalışmalarda kompomerlerin Cİs ve RMCİS'lere göre daha düşük düzeyde florür salımı yaptığı belirlenmiştir. Bantların yapıştırımasında kullanılan Unitek Multicure (3M-ESPE), Ultra Band-Lok (Reliance), Fuji Ortho Band Paste Pak (GC), Meron (Voco) gibi materyallerin florür salımı yapabildiği gösterilmiştir ${ }^{20,49}$. Braketlerin yapıştırılmasında kulanıIan Fuji Ortho LC (GAC), Unitek (3M-ESPE), Assure (Reliance), FluorEver (Macro Chem) gibi materyallerin de florür salımı yapabildiği bildirilmiştir ${ }^{50-52}$. Ancak özellikle CİS ve RMCİS'ler, diş macunu ya da florürlü ağız gargarası gibi günlük florür uygulamaları ile yeniden florürle yüklenebilmekte ve ağızda bir florür deposu görevi gördüklerinden rezin esaslı materyallerden daha etkin olabilmektedirler ${ }^{16,49}$.

Son yıllarda ağızda florür salımını sağlayan ürünler arasında elastomerik ligatürler de göze çarpmaktadır. Florür içeren elastomerik ligatürlerden ilk 24 saatte yüksek düzeyde bunu izleyen günlerde florür düzeyinin azaldığı bildirilmiştir. İlk iki haftada florürin \%90'a yakınını serbestleyen ligatürlerin ayda bir değiştirilmesinin en uygun sonuçların alınabilmesi için gerekli olduğu ileri sürülmüştür ${ }^{52}$. Banks ve ark. ${ }^{25}$ kalay florür salımı yapan elastomerik ligatürlerin ayda bir değiştirilerek kullanıldığında, dekalsifikasyonda \% 49 oranında bir azalma sağladığını göstermiş̧lerdir. Bununla birlikte, florür salımı yapan elastomerik ligatürlerin klinik olarak demineralizasyonu önleyici etkisini bir in situ model üzerinde, mineral kaybı, lezyon genişliği ve derinliği açısından inceleyen Doherty ve ark. ${ }^{53}$, ortodontik tedavi gören hastalar için çürük önleyici bir etki belirleyemediklerini, yerel etkilerin araştırılması gerektiğini bildirmişlerdir.

Yüzeysel florür uygulamalarının braketlerin bağlanma kuvvetlerine etkisi tartışılmaktadır. Konu ile ilgili literatürlerde, florür uygulamalarının ortodontik tedavi ile birlikte kullanımında çeşitli yöntemlerin önerildiği görülmektedir. Minenin yapıştırma öncesi temizlenmesinde ${ }^{54,55}$, asitle pürüzlendirme öncesin$\mathrm{de}^{56}$, asitle pürüzlendirme sırasında ${ }^{57}$ ve braket yapıştırma öncesinde ${ }^{58,59}$ uygulanabilen yerel florürlerin bağlanma kuvvetini in vitro koşullarda inceleyen çok sayıda araştırma bulunmaktadır. Braketlerin yapıştırılmasından önce yapılan profesyonel temizlik işleminde florür içeren patlar kullanılmasının braketlerin bağlanma kuvvetlerine olumsuz bir etkisi olmadığı ve asitle pürüzlendirme öncesinde kullanılabilecekleri bildirilmiştir ${ }^{54,55}$. Bryant ve ark. ${ }^{59}$; çeşitli yüzeysel florür ajanlarının asitle pürüzlendirmeden 7 gün önce uygulanmasının minenin florür konsantrasyonunu yükselttiğini ve bağlanma kuvvetlerini ters yönde etkilemediğini bildirmişlerdir. Kimura ve ark. ${ }^{56}$; braketlemeden 10 gün once florür verniği uygulanan diş örneklerinde self-etching primer ve geleneksel adeziv kullanılarak yapılan braketlemede bağlanma kuvvetlerinin kontrol grubuna göre anlamlı bir farklılık göstermediğini ve kopmaların genelde braket ile rezin arasında gerçekleştiğini bildirmişlerdir. Asitle pürüzlendirmeden hemen önce APF uygulamasının ise bağlanma kuvvetlerini anlamlı düzeyde azalttığı bildirilmiştir ${ }^{58}$. Minenin pürüzlendirilmesinde kullanılan asit jellerinin içine florür katılmasının da bağlanma kuvvetlerini etkilemediği ve florür içermeyen jellere benzer düzeyde bağlanma sağlayabildikleri görülmüş ve ortodontik braketlerin çevresinde ve altında demineralizasyon ve çürük oluşumunun önlenmesinde bu yöntemin kullanılabileceği ileri sürülmüştür ${ }^{57}$. Braketin yapıştırılmasından önce ve asitle pürüzlendirmeden sonra florür uygulanmasının ise bağlanma kuvvetlerini azalttığı ${ }^{58,59}$ ve braketlerin çıkarılması sırasında mineden kopmalara neden olabileceği bildirilmiştir ${ }^{57}$.

\section{Klorheksidin Uygulamaları}

Çürük aktivitesi yüksek bireylerde, diş fırçalama sıklığının arttırıması veya yüksek dozda florür uygulanması demineralizasyon sürecini etkili bir biçimde durdurmaya yeterli olmamaktadır ${ }^{60}$. Bu nedenle ortodontik tedavi gören yüksek risk grubundaki bireylerde ağız hijyeninin iyileştirilmesinin yanında, çürük yapıcı mikrofloranın kemoterapötik ajanlar yardımı ile baskılanması gerekmektedir ${ }^{61}$. Kemoteröpatik ajanlardan klorheksidin, S.mutans üzerinde etkinliği en iyi bilinen antimikrobiyal ajandır ${ }^{62}$. Ortodontik tedavi gören hastalarda klorheksidin verniği uygulamasının tükürük ve dental plaktaki bakteri ve özellikle de S.mutans düzeylerini anlamlı düzeyde azalttığını bildiren araştırmalar bulunmaktadır ${ }^{23,61}$. Ancak klorheksidinin uzun dönem günlük kullanımı sıklıkla diş ve dilin renklenmesi ve ağızda metal tat bırakmasından dolayı tavsiye edilmemektedir ${ }^{14}$. 
Øgaard ve ark. $^{60}$ ortodontik tedavi gören bireylerde klorheksidin verniği ile florür verniğinin kombine uygulanmasının beyaz nokta lezyonu oluşumunu önlemede florür verniğinin tek başına uygulanmasına göre bir üstünlüğü bulunmadığını, yalnız üst kesici dişler bölgesinde her iki yöntemin kombine kullanımının beyaz nokta lezyon oluşumunu daha etkili bir şekilde azaltma eğiliminde olduğunu bildirmişlerdir.

Ortodonti hastalarında \% 0,2'lik klorheksidin gargarasının plağın gelişimine etkisini florür içeren bir diş macunu ile karşılaştıran bir çalışmada, klorheksidin grubunda S.mutansların tamamına yakınıın elimine edildiği gösterilmiştir. Klinik parametreler değerlendirildiğinde ise, ortodontik tedavi sırasında plak birikimi ile ilgili yan etkilerin azaltılması ve ağız hijyeni işlemlerinin etkisinin arttırıması için, \% 0,2'lik klorheksidin gargara uygulamasının profesyonel bakım ve hastanın ağız hijyeni açısından eğitilmesi gibi diğer koruyucu yöntemlere ek olarak belirli aralıklarla kullanılabileceği bildirilmiştir ${ }^{63,64}$.

Attin ve ark. ${ }^{65}$ sabit ortodontik tedavi gören ve dişlerinde yoğun S.mutans kolonizasyonu olduğu belirlenen bireylerde \%36'lık klorheksidin içeren vernik uygulamasından 2 hafta sonra S.mutans sayısının başlangıç değerlerine dönmeye başladığını ve başlangıç ve 2 hafta sonraki değerler arasındaki farkın çok az olduğunu belirlemişlerdir. Araştırmacılar sonuç olarak, \%36'lık klorheksidin verniğinin bir kez uygulanmasının sabit ortodontik tedavi gören ve yüksek S.mutans kolonizasyonuna sahip bireylerde bakteri sayısını baskılamaya yeterli olmadığını bildirmişler ve daha etkili tedavi yöntemlerinin geliştirilmesi gerektiğini ileri sürmüşlerdir. Farret ve ark. ${ }^{66}$; bant yapışırmada kullanılan farklı cam iyonomer simanlara klorheksidin diglukonat eklenmesinin, mekanik ve antibakteriyel özellikler üzerine etkilerini inceledikleri çalışmalarında; hem \% 10'luk hem de $\% 18^{\prime}$ lik klorheksidin diglukonat grubunda mekanik özelliklerin olumsuz etkilenmediğini; antibakteriyel etkilerin ise uzun dönem devam ettiğini bildirilmişlerdir. Cacciafesta ve ark. ${ }^{58}$, çalışmalarında bondingden önceki klorheksidin uygulanan ve önce bir hafta klorheksidin uygulayıp takip eden hafta klorheksidin içermeyen gargaralar kullandırmışlardır. Çalışma sonuçlarına göre bondingin hemen öncesinde klorheksidin uygulamasının bağlanma kuvvetlerini olumsuz etkilediğini bildirmişlerdir.

\section{Diğer Uygulamalar Ksilitol}

Doğal bir şeker alkolü olan ksilitolün fermente olmayan bir karbonhidrat olduğu için dental plaktaki S.mutans çoğalmasını ve büyümesini önlediği; mine demineralizasyon ve remineralizasyon işlemini direk olarak etkileyebildiği belirtilmektedir ${ }^{14,23}$. Piyasada ksilitol içeren sakızlar ve ağızda eriyen pastil şeklinde bulunmaktadır. Ortodontik tedavi gören bireylerin sakız çiğnemesi önerilmediğinden pastillerin kullanımı daha yararlı bulunmaktadır. ${ }^{67}$ Sengun ve ark. ${ }^{68}$ sabit ortodontik tedavi uygulanan vakalarda xylitol pastillerin plak pH'ına etkisini değerlendirmişler ve sonuç olarak olası dental çürüklerin önlenmesi amacıyla bu preparatın kullanımasını tavsiye etmişlerdir. Bunun yanı sıra, yine ortodontik tedavi gören bireylerde ksilitol tabletlerinin S.mutans sayısı üzerine etkisini inceleyen başka bir klinik çalışmada düşük dozda ksilitolün düzenli olarak hergün kullanılmasının ilk 6 haftada S.mutans düzeylerinde azalmaya yol açtığı, ancak bu etkinin uzun dönem devam etmediği gösterilmiştir ${ }^{69}$.

\section{Kazein Fosfopeptid Amorf Kalsiyum Fosfat (CPP-ACP)}

Ortodontik tedavi gören hastalarda kazein fosfopeptid amorf kalsiyum fosfat (CPP-ACP) remineralizasyonu artırmak için kullanılmaktadır. CPPACP solusyon olarak, sakızlarda ve diş macunlarının içerisinde bulunmaktadır. Yapılan çalışmalarda sakız içerisine eklenen CPP-ACP nin remineralizasyonu zenginleştirdiği gözlenmiştir. Ancak bu durumun CPPACP'den mi kaynaklandığı yada sakızların kullanımılla tükürük uyarılmasından dolayı mı kaynaklandığı soru işaretidir ${ }^{70,71}$. Şekersiz sakız kullanımı genellikle sabit ortodontik apareylerin kullanılmasından sonra tavsiye edilmektedir. Tükürük kontrolünü riske atan bölgelere bu ajanı uygulamak, çözülme potansiyeli olan bölgelerde, çökelme için uygun kalsiyum ve fosfatı oluşturabilir ${ }^{14}$.

\section{SONUÇ}

Toplumumuzda ağız sağlığı ile ilgili bilinç düzeyi ve ağız bakımı yetersiz olmakla beraber ortodontik tedavi görecek hastalar için bu durum daha fazla önem kazanmaktadır. Ağız hijyeni yetersiz bireylerde ortodontik tedaviler yarar sağlamaktan çok zarar verici olabilmektedir. Bu nedenle ortodontik tedavinin 
hastanın yararına olması için, getirdiği avantajların oluşturabileceği zararlardan daha fazla olması gerekmektedir.

Çürük riski değerlendirmesi sonucunda düşük risk grubunda yer aldığı belirlenen bireylerde ortodontik tedavi sırasında; beslenme kontrolu, düzenli hasta motivasyonu seansları, florür uygulamaları dekalsifikasyonların önlenmesinde yeterli olabilmektedir. Ancak yüksek risk grubunda yer alan bireyler için düzenli profesyonel diş ve diştaşı temizliği ve florür uygulamalarına ek olarak kemoteröpatik ajanların kullanılması önerilmektedir.

\section{KAYNAKLAR}

1. Pinkham JR, Casamassimo PS, Fieşds HW, MC Tigue DJ, Nowak AJ. Çocuk Diş Hekimliği. Tortop T, Tulunoğlu Ö (çev.), 4. baskı. Atlas Kitapçılık. 2009. p. 153-64.

2. McDonald RE, Avery DR, Dean J. Dentistry for Child and Adolescent 8th ed. Mosby. 2004. p. 23656.

3. Şahin S, Saygun I, Enhoş Ş, Akyol M, Altuğ A, Tekbaş Ö.F. Eğitim Düzeyinin Genç Erişkin Erkeklerde Ağiz Sağliğina Etkisinin Değerlendirilmesi. GÜ Diş Hek Fak Derg 2009;3:133-40.

4. Öztunç $H$, Haytaç $M C$, Özmeriç N, Uzel İ. Adana İlinde 6-11 yaş grubu çocukların ağız-diş sağığı durumlarının değerlendirilmesi. GÜ Diş Hek Fak Derg 2000;17:1-6.

5. Demirer S, Çatalbaş B, Gelgör İE, Görür T, Karşıyaka M. Ortodontik tedaviye başvuran çocuklar ve ebeveynlerinin ağız sağlığı bilinç düzeyleri, ağız bakımı ve ağız sağlığı durumlarının karşılaştırılması: Ön çalışma. SÜ Diş Hek Fak Derg 2010;19:26-34.

6. Löe $H$. Oral hygiene in the prevention of caries and periodontal disease. Int Dent J 2000;50:129-39.

7. WHO Oral Health-The CAPP index; http://www.whocollab.od.mah.se/index.html; accessed March 20, 2001.

8. Sanchez AA, Lau-Rojo L, Leon-Viedas PL. Socioeconomic and sociodemographic variables associated with oral hygiene status in Mexican schoolchildren aged 6 to 12 years. J Periodontol 2007;78:816-22.
9. Astrom NA, Jakobsen R. The effect of parental dental health behavior on that of their adolescent offspring. Acta Odontol Scand 1996;54:235-41.

10. Efe E, Sarvan S, Kukulu K. Self-reported knowledge and behaviors related to oral and dental health in Turkish children. Issues Compr Pediatr Nurs 2007;30:133-46.

11. Bozkurt FY, Kıran M. Yetiştirme Yurdunda Kalan 12-16 Yaş Grubu Bireylerde Ağiz Sağliği Bulguları. CÜ Diş Hek Fak Derg 2005;8:31-7.

12. Tulunoğlu Ö, Bodur H, Akal N. Aile Eğitim Düzeyinin Okul Öncesi Çocuklardaki Ağiz Diş Sağliği Uygulamalari Üzerine Etkisinin Değerlendirilmesi. GÜ Diş Hek Fak Derg 1999;16:27-32.

13. Call RL. Effects of proverty on children's dental health. Pediatrician 1989;16:200-6.

14. Noble J, Cassolato S, Karaikos N, Wiltshire WA. Point of Care. JCDA 2009;75:441-3.

15. Costa MR, da Silva VC, Miqui MN, Colombo AP, Cirelli JA. Effects of ultrasonic, electric, and manual toothbrushes on subgingival plaque composition in orthodontically banded molars. Am J Orthod Dentofacial Orthop 2010;137:229-35.

16. Uysal T, Amasyalı M, Koyutürk AE. Ortodontide beyaz nokta lezyonları ve güncel teşhis, korunma ve Tedavi yaklaşımları. CÜ Diş Hek Fak Derg 2009;12:152-61.

17. Beberhold K, Sachse-Kulp A, Schwestka-Polly R, Hornecker E, Ziebolz D. The Orthodontic Plaque Index: An oral hygiene index for patients with multibracket appliances. Orthodontics (Chic.) 2012; 13:94-9.

18. Erdem S, Arun T. Ortodontik Tedavi Sırasında Demineralizasyonun Önlenmesi. YÜ Diş Hek Fak Derg 2008;2:14-8.

19. Baydaş B, Kavrut F. Ortodontik Tedavi Gören Bireylerde Farkli Gargaraların Ağiz Sağliğına Etkilerinin Değerlendirilmesi. AÜ Diş Hek Fak Derg 2005;15:12-21.

20. Ay ZY, Sayın MÖ, Yener Ö, Göster T, Atilla AO, Bozkurt FY. Appropriate Oral Hygiene Motivation Method for Patients with Fixed Appliances. Angle Orthod 2007;77:1085-9.

21. Babacan H, Sokucu O, Marakoğlu İ, Ozdemir H, Nalçacı R. Effect of fixed appliances on oral malodor. Am J Orthod Dentofac Orthop 2011;139:351-5. 
22. Tufekci E, Dixon JS, Gunsolley JC, Lindauer SJ. Prevalence of white spot lesions during orthodontic treatment with fixed appliances. Angle Orthod 2011;81:206-10.

23. Kuvvetli SS, Sandallı N. Sabit Ortodontik Tedavi Gören Hastalarda Ağız Hijyeninin Sağlanması ve Diş Çürüklerinin Önlenmesi. EÜ Diş Hek Fak Derg 2006;27:135-44.

24. Lalic M, Aleksic E, Gajic M, Milic J, Malesevic D. Does oral health counseling effectively improve oral hygiene of orthodontic patients? Eur J Paediatr Dent 2012;13:181-6.

25. Banks PA, Chadwick SM, Asher-McDade C, Wright JL. Fluoride-releasing elastomerics- a prospective controlled clinical trial. Eur J Orthod 2000;22:4017.

26. Nanda R. Biomechanics And Esthetic Strategies In Clinical Orthodontics. Elsevier Saunders. 2005.p.57.

27. Rosenbloom RG, Tinanoff N. Salivary Streptococcus mutans levels in patients before, during, and after orthodontic treatment. Am J Orthod Dentofac Orthop 1991;100:35-7.

28. Lundström F, Krasse $B$. Caries incidence in orthodontic patients with high levels of Streptococcus mutans. Eur J Orthod 1987;9:11721.

29. Beyth N, Redlich M, Harari D, Friedman M, Steinberg D. Effect of sustained-released chlorhexidine varnish on Streptoccus mutans and Actinomyces viscosus in orthodontic patients. Am J Orthod Dentofac Orthop 2003;123:345-8.

30. Gorelick L, Geiger AM, Gwinett AJ. Incidence of white spot formation after bonding and banding. Am J Orthod 1982;81:93-8.

31. Policy on use of a Caries-risk Assessment Tool (CAT) for Infants, Children and Adolescents. American Academy of Pediatric Dentistry Oral Health Policies, 2006.

32. Zimmer BW, Rottwinkel Y. Assessing paitentspecific decalcification risk in fixed orthodontic treatment and its impact on prophylactic procedures. Am J Orthod Dentofac Orthop 2004;126:318-24.

33. Yip HHY, Wong RWK, Hagg U. Complications of orthodontic treatment: Are soft drinks a risk factor? World J of Orthod 2009;10:33-40.

34. http://www.sign.ac.uk/pdf/sign47.pdf Preventing dental caries in children at high caries risk. A National Clinical Guideline. Sign publ. 2000.

35. Bowen DM. Mechanical Plaque Control: Toothbrushes and Toothbrushing. In: Darby $\mathrm{ML}$, Walsh MM. Dental Hygiene Theory and Practice 2nd Ed., Saunders, St. Louis, Missouri: 2003.p.348-59.

36. Gomes LK, Sarmento CF, Seabra FRG, Santos PBD, Pinheiro FHSL. Randomized clinical controlled trial on the effectiveness of conventional and orthodontic manual toothbrushes. Braz Oral Res 2012; 26: 360-5.

37. Clarehugh V, Williams $P$, Shaw WC, Worthington $\mathrm{HV}$, Warren P. A practice based randomised controlled trial of the efficacy of an electric and a manual toothbrush on gingival health in patients with fixed orthodontic appliances. J Dent 1998;26:633-9.

38. Heasman P, Wilson Z, Macgregor I, Kelly P. Comparative study of electric and manual toothbrushes in patients with fixed orthodontic appliances. Am J Orthod Dentofac Orthop 1998;114:45-9.

39. Costa MR, Silva VC, Miqui MN, Sakima $T$ et al. Efficacy of ultrasonic, electric and manual toothbrushes in patients with fixed orthodontic appliances. Angle Orthod 2007;77:361-6.

40. Hickman J, Millet DT, Sander L, Brown E, Love J. Powered vs manual tooth brushing in fixed appliance patients: A short term randomized clinical trial. Angle Orthod 2002;72:135-40.

41. Kilicoglu $H$, Yidirim M, Polater $H$. Comparison of the effectiveness of two types of brushes on the oral hygiene of patients undergoing orthodontic treatment with fixed appliances. Am J Orthod Dentofac Orthop 1997:111:591-4.

42. Kossack C, Jost-Brinkmann PG. Plaque and Gingivitis Reduction in Patients Undergoing Orthodontic Treatment with Fixed AppliancesComparison of Toothbrushes and Interdental Cleaning Aids A 6-Month Clinical Single-Blind Trial. J Orofac Orthop 2005;66:20-38.

43. Øgaard B, Alm AA, Larsson E, Adolfsson U. A prospective, randomized clinical study on the effects of an amine fluoride/stannous fluoride toothpaste/mouthrinse on plaque, gingivitis and initial caries lesion development in orthodontic patients. Eur J Orthod 2006;28:8-12. 
44. Willmot DR. White lesions after orthodontic treatment: does low fluoride make a difference? J Orthod 2004;31:235-42.

45. Soliman MM, Bishara SE, Wefel J, Heilman J, Warren J]. Fluoride release rate from an orthodontic sealant and its clinical implications. Angle Orthod 2006;76:282-88.

46. Hu W, Featherstone JD. Prevention of enamel demineralization: an in-vitro study using lightcured filled sealant. Am J Orthod Dentofac Orthop 2005; 128:592-600.

47. Varlık SK, Demirbaş E. Effect of light-cured filled sealent on the bond failure of orthodontic brackets in vivo. Am J Orthod Dentofac Orthop 2009;144:e1-4.

48. Tuncer C, Tuncer BB, Ulusoy Ç. Effect of fluoridereleasing light-cured resin on shear bond strength of orthodontic brackets. Am J Orthod Dentofac Orthop 2009; 135:14.e1-6.

49. Komori A, Kojima I. Evaluation of a new 2-paste glass ionomer cement. Am J Orthod Dentofac Orthop 2003;123:649-52.

50. Creanor SL, Al-Harty NS, Gilmour WH, Foye RH, Rogers I, Millett DT. Fluoride release from orthodontic cementseffect of specimen surface area and depth. J Dent 2003;31:25-32.

51. Wheeler AW, Foley TF, Mamandras A. Comparison of fluoride release protocols for in-vitro testing of 3 orthodontic adhesives. Am J Orthod Dentofac Orthop 2002;121:301-9.

52. Evrenol BI, Küçükkeleş N, Arun T, Yarat A. Fluoride release capacities of four different orthodontic adhesives. J Clin Pediatr Dent 1999;23:315-20.

53. Doherty UB, Benson PE, Higham SM. Fluoridereleasing elastomeric ligatures assessed with the in situ caries model. Eur J Orthod 2002;24:371-8.

54. Damon PL, Bishara SE, Olsen ME, Jakobsen JR. Effects of fluoride application on shear bond strength of orthodontic brackets. Angle Orthod 1996;66:61-4.

55. Cacciafesta V, Sfondrini MF, Calvi D, Scribante A. Effect of fluoride application on shear bond strength of brackets bonded with a resin-modified glass-ionomer. Am J Orthod Dentofac Orthop 2005;127:580-3.
56. Kimura T, Dunn WJ, Taloumis LJ. Effect of fluoride varnish on the in vitro bond strength of orthodontic brackets using a self-etching primer system. Am J Orthod Dentofac Orthop 2004;125:351-6.

57. Meng $\mathrm{CL}$, Wang WN, Yeh IS. Fluoridated etching on orthodontic bonding. Am J Orthod Dentofac Orthop 1997;112:259-62.

58. Cacciafesta V, Sfondrini MF, Calvi D, Scribante A. Effect of fluoride application on shear bond strength of brackets bonded with a resin-modified glass-ionomer. Am J Orthod Dentofac Orthop 2005; 127:580-3.

59. Bryant S, Retief DH, Bradley EL Jr, Denys FR. The effect of topical fluoride treatment on enamel fluoride uptake and the tensile bond strength of an orthodontic bonding resin. Am J Orthod 1985;87:294-302.

60. Øgaard B, Larsson E, Henriksson T, Birkhed D, Bishara SE. Effects of combined application of antimicrobial and fluoride varnishes in orthodontic patients. Am J Orthod Dentofac Orthop 2001;120:28-35.

61. Attin R, Tuna A, Attin T, Brunner E, Noack MJ. Efficacy of differently concentrated chlorhexidine varnishes in decreasing mutans streptococci and lactobacilli counts. Arch Oral Biol 2003;48:503-9.

62. Fardal O, Turnbull RS. A review on the literature on use of chlorhexidine in dentistry. J Am Dent Assoc 1986;112:863-9.

63. Gehlen I, Netuschil L, Berg R, Reich E, Katsaros C. The influence of a $0.2 \%$ chlorhexidine mouthrinse on plaque regrowth in orthodontic patients. A randomized prospective study. Part I: clinical parameters. J Orofac Orthop 2000;61:54-62.

64. Baydaş B, Kavrut F. Ortodontik Tedavi Gören Bireylerde Farklı Gargaraların Ağız Sağlığına Etkilerinin Değerlendirilmesi. Atatürk Üni Diş Hek Fak Derg 2005;15:1-12.

65. Attin R, Ilse A, Werner C, Wiegand A, Attin T. Antimicrobial effectiveness of a highly concentrated chlorhexidine varnish treatment in teenagers with fixed orthodontic appliances. Angle Orthod 2006;76:1022-7.

66. Farret M.M, De Lima E.M, Mota E.G, Oshimo H.M.S, Barth V, De Oliviera S.D. Can we add chlorhexidine into glass ionomer cements for band cementation? Angle Orthod 2011;81:496-502.

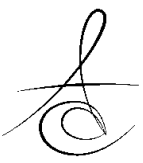


67. Çatalbaş B, Ercan E, Erdemir A, Gelgör İ.E, Zorba Y.O. Effects of Different Chlorhexidine Formulations on Shear Bond Strengths of Orthodontic Brackets. Angle Orthod 2008;79:31216.

68. Sengun A, Sari Z, Ramoglu SI, Malkoc S, Duran I. Evaluation of the dental plaque $\mathrm{pH}$ recovery effect of a xylitol lozenge on patients with fixed orthodontic appliances. Angle Orthod 2004;74:240-4.

69. Stecksen-Blicks C, Holgerson PL, Olsson M et al. Effect of xylitol on mutans streptococci and lactic acid formation in saliva and plaque from adolescents and young adults with fixed orthodontic appliances. Eur J Oral Sci 2004;112:244-8.

70. Iijima Y, Cai F, Shen P, Walker G, Reynolds C, Reynolds EC. Acid resistance of enamel subsurface lesions remineralized by sugar free chewing gum containing phosphopeptide-amorphous calcium phosphate-amorphous calcium phosphate. Caries Res 2004;38:551-6.

71. Reynolds EC, Cai F, Shen P, Walker GD. Retention in plaque and remineralization of enamel lesions by various forms of calcium in a mouthrinse or sugarfree chewing gum. J Dent Res 2003,82:206-11.

\section{Yazışma Adresi}

Dr. Mehmet Bani

Adres: Gazi Üniversitesi Diş Hekimliği Fakültesi Pedodonti Anabilim Dalı

B blok 5.kat Emek Çankaya ANKARA

Tel: 03122034088

Fax: 03122239226

e-posta: mehmetbani@hotmail.com 